\title{
A UTILIZAÇÃO DE GÁS COMBUSTÍVEL EM SUBSTITUIÇÃO À ELETRICIDADE NO AQUECIMENTO DOMÉSTICO DE ÁGUA
}

\author{
YUKIO KAVASSAKI \\ MARINA SANGOI DE OLIVEIRA ILHA \\ ORESTES MARRACINI GONÇALVES ${ }^{b}$
}

KAVASSAKI, Y.; ILHA, M.S. de; GONÇALVES, O.M. A utilização de gás combustível em substituição à eletricidade no aquecimento doméstico de água. Semina, v. 12, n. 4, p.230-235, dez. 1991.

\section{RESUMO}

O contexto de crise energética sugere medidas de conservação e de uso efetivo das formas primárias de energia, no sentido de compatibilizar a sua disponibilidade com a demanda sempre crescente. O espectro de usos de energia elétrica, no setor residencial, evidencia a grande incidência no aquecimento de água, responsável por picos de carga. Assim, neste trabalho, avalia-se, técnica e economicamente, diversos casos de substituição de eletricidade por gás combustível no aquecimento de água, tanto em edificações novas quanto em edificações habitadas.

PALAVRAS-CHAVE: Água quente, Sistemas prediais de água quente, Aquecimento de água, Conservação de energia.

\section{1 - INTRODUÇÃO}

Cada vez mais, a nível internacional, espraia-se a consciência de que apenas medidas de conservação e de uso efetivo das formas primárias de energia permitirão uma real contribuição, no sentido de compatibilizar a demanda crescente por energia utilizável com a sua própria disponibilidade, na maioria dos casos limitada.

É possível constatar o alto custo social da implantação de um KW adicional de energia elétrica em cidades como São Paulo, devido, em especial, à escassez do referido insumo. Em contrapartida, observa-se um incentivo cada vez maior à utilização de gás combustível nestas grandes concentrações urbanas, sugerindo a implementação de uma política de substituição de energético, particularmente em edifícios residenciais.

A análise do espectro de usos de energia elétrica do setor residencial, por sua vez, revela a grande incidência no aquecimento de água, responsável por picos de carga. Do ponto de vista prático, percebe-se, facilmente, a extensão do impacto que produzirá a substituição de energético no aquecimento de água para o setor residencial, uma vez que haverá um alívio significativo na pressão de demanda de energia elétrica, especialmente nos horários de pico.

Este contexto, em conseqüência, justifica o desenvolvimento de tecnologias de substituição de sistemas elétricos de aquecimento de água para sistemas a gás combustível, tanto em edificações novas quanto em edificações habitadas.

\section{2 - MATERIAL E MÉTODO}

\subsection{Definição das Tipologias de Edificações}

A metodologia para estabelecer a tipologia ou o padrão de edifícios residenciais, que refletisse a construção média das edificações para fins habitacionais em São Paulo, baseou-se em levantamento de dados cadastrais, referentes a onze anos, junto a órgãos governamentais e entidades privadas. A partir dos dados obtidos, procurou-se, estatisticamente, caracterizar padrões de edificações para fins habitacionais quanto a: número de dormitórios, número de banheiros, área útil e número de apartamentos por andar, de forma a resultar em algumas tipologias de edificações, nas quais fossem possíveis os estudos das alternativas de abastecimento de gás (para cocção, aquecimento, etc.) e de distribuição de água quente.

A partir da análise dos dados disponíveis (Iançamentos de 1977 a 1988, no Município de São Paulo), escolheuse as seguintes tipologias como as mais representativas para o estudo (cerca de $60 \%$ e $15 \%$, respectivamente) em edificações habitadas:

Tipologia 1 - Edifício de 4 apartamentos por andar com 2 dormitórios e 1 banheiro por apartamento.

Tipologia 2 - Edifício de 2 apartamentos por andar com 3 dormitórios e 2 banheiros por apartamento,

$\mathrm{Na}$ definição das tipologias das edificações, transpareceu, nitidamente, a preocupação com a escala de aplica-

a Departamento de Construção Civif/CTU - Universidade Estadual de Londrina, Caixa Postal, 6001, CEP 86051-970, Londrina - Paraná Brasil.

Departamento de Engenharia de Construção Civil / Escola Politécnica da USP. 
cão das soluções finais a serem detalhadas. Assim, duas tipologias adicionais, de características peculiares interessantes em termos dos objetivos do presente estudo, foram apreciadas:

Tipologia 3 - Edifício de apartamentos da COHAB. Tipologia 4 - Edifício de apartamentos de alto padrão.

A habitação multi-familiar de interesse social utiliza, eminentemente, o chuveiro elétrico, de modo que o desenvolvimento de alternativas de substituição de energético apresentará grande alcance, face à receptividade dessa modalidade de edificação, além dos benefícios sociais resultantes dos menores custos inicial e operacional envolvidos. O interesse pela Tipologia 4 deve-se ao fato de apresentar, tipicamente, grandes distâncias no que se refere ao traçado das redes e um ou mais aquecedores elétricos, apesar da existência de instalação predial de gás combustível para cocção.

No caso de edificações novas, por outro lado, considerou-se apenas as Tipologias 1, 3 e 4.

\section{2 - Estudo de Alternativas de Substituição de Energético no Aquecimento Doméstico de Água.}

\subsection{1 — Sistemas Prediais de Água Quente.}

No sentido de obter consistência da classificação com relação aos objetivos específicos deste estudo, os sistemas prediais de água quente são subdivididos inicialmente segundo a fonte energética utilizada no aquecimento:

- aquecimento a gás combustível;

- aquecimento a eletricidade;

- aquecimento através de outras fontes de energia.

O aquecimento através de fontes alternativas de energia pressupõe a utilização de óleo combustível, lenha, biogás, carvão mineral, energia solar e combinações destas, entre outras, as quais não constituem escopo deste trabalho.

Por sua vez, quanto à modalidade de geraçao/reservação e distribuição de água quente, os sistemas estão classificados em central (coletivo e privado) e individual.

O sistema central compreende, basicamente, um equipamento responsável pelo aquecimento da água e uma rede de tubulações, através da qual a água quente é distribuída, alimentando conjuntos de aparelhos. Este tipo de sistema pode ser coletivo, quando os conjuntos de aparelhos pertencem a várias unidades (ex: edifício de apartamentos) ou privado, quando pertencem a uma mesma unidade (ex.: apartamento). No sistema central coletivo, tem-se, sempre, a reservação de um volume de água a ser aquecido, enquanto que no privado pode se ter reservação de água (aquecedor de acumulação) ou não, caso este em que a água vai sendo aquecida à medida que passa pela fonte de aquecimento (aquecedor de passagem ou instantâneo).

O sistema individual de aquecimento, de outro lado, consiste na alimentação de um único ponto de utilização, sem necessidade de uma rede de água quente (ex: chuveiro elétrico).

\subsection{2 - Seleção das Alternativas}

\subsubsection{1 - Edificações Habitadas}

Uma vez definidos os tipos de sistemas prediais de água quente, efetuou-se uma análise técnica preliminar, procurando estabelecer a intervenção necessária nas edificações habitadas, de modo a identificar as alternativas mais viáveis a serem detalhadas a nível de Projeto Executivo.

Assim sendo, para a escotha das alternativas, levouse em consideração os seguintes aspectos:

- facilidade de execução das redes de água fria e água quente;

- facilidade de manutenção das redes de água fria e água quente;

- comodidade ao usuário (transtornos de instalação, medição, rateio de contas, etc.\};

- economia (custo de implantação do sistema por apartamento);

- grau de ocorrência do sistema existente;

- dificuldade no traçado da rede;

- adequação do ambiente, etc.

\subsubsection{2 - Edificações Novas}

Definidas as tipologias, foram estudados os projetos tecnicamente mais adequados para cada uma delas, considerando-se o tipo de sistema de geração/reservação e de distribuição de água quente, que são os seguintes:

- Tipologia 1: avaliou-se a possibilidade de implantação dos sistemas central privado e central coletivo, examinando-se também a questão da medição individualizada de água quente no sistema central coletivo, com o objetivo de ratear o energético utilizado no aquecimento de água;

- Tipologia 3: estudou-se apenas o sistema centra! privado (com aquecedor instantâneo);

- Tipologia 4: como no caso da Tipologia 1, foram estudados os sistemas central privado e central coletivo, além da questão da medição individualizada de água quente no sistema centra! coletivo.

\subsection{3 - Projetos e Orçamentos}

Para as dezesseis alternativas de projeto de instalações de água quente selecionadas na avaliação técnica, foram elaborados os respectivos Projetos Executivos, de acordo com dimensionamento realizado a partir de modelagem probabilística, proposta por GONÇALVES (1986), para o estabelecimento das vazões. Em seguida, efetuadas as quantificações de materiais e de mão-de-obra para execução, foram definidas as planilhas de orçamento para cada alternativa.

Por outro lado, uma vez que, atualmente, é obrigatória a existência de instalação de gás combustível em edificações residenciais, seja ela para gás de rua ou para GLP 
(gás liqüefeito de petróleo), procurou-se avaliar a possibilidade de implantar um sistema de aquecimento de água a gás combustível, eliminando-se toda a parte elétrica correspondente ao aquecimento de água. Em outras palavras, até que ponto a economia obtida com a retirada de tais previsões, na instalação elétrica, pode amortizar o equipamento ou mesmo a instalação de água quente, quando da especificação de gás combustível para o aquecimento de água, no caso de edificações novas. Para tanto,
- o equipamento de aquecimento de água encarece sobremaneira a substituição; portanto, deve-se levar em conta o estado de conservação do equipamento existente (depreciação), pois este pode estar em vias de ser substituído, constituindo um gasto que o(s) usuário(s) teria(m) mesmo de arcar.

A fim de ilustrar a influência do equipamento, em termos percentuais, no custo da instalação, apresenta-se a Tabela 2 referente à Tipologia 1 .

TABELA 1 - Custo da substituição do energético para aquecimento de água nas diferentes Tiplogias em US\$/apartamento

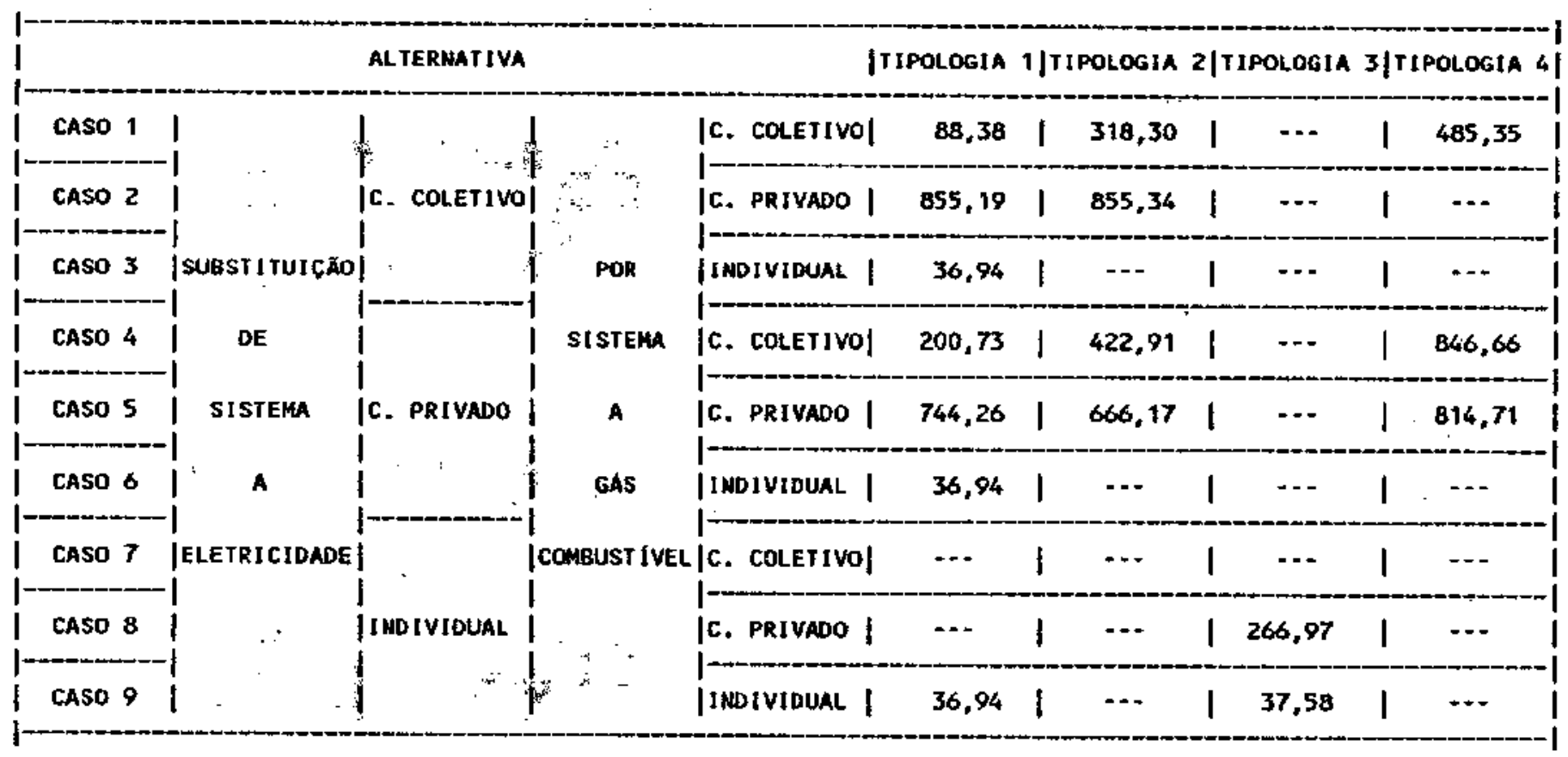

foram elaborados os projetos de instalações elétricas com e sem as "referidas previsões, e levantados os respectivos custos.

\section{3 - RESULTADOS E DISCUSSÃO}

\section{1 - Edificações Habitadas}

Analisando-se as Tabelas 1 e 2, observa-se que:

- a viabilidade do sistema central coletivo (caldeira) tende a aumentar, à medida que cresce o número de apartamentos no edifício, pois assim a parcela correspondente a cada apartamento, no rateio, torna-se menor; tal fato não ocorre com o sistema central privado, uma vez que cada apartamento deve adquirir o seu próprio equipamento, independentemente do número de apartamentos no edifício;
TABELA 2 - Tipologia 1: Influência dos aquecedores no custo.

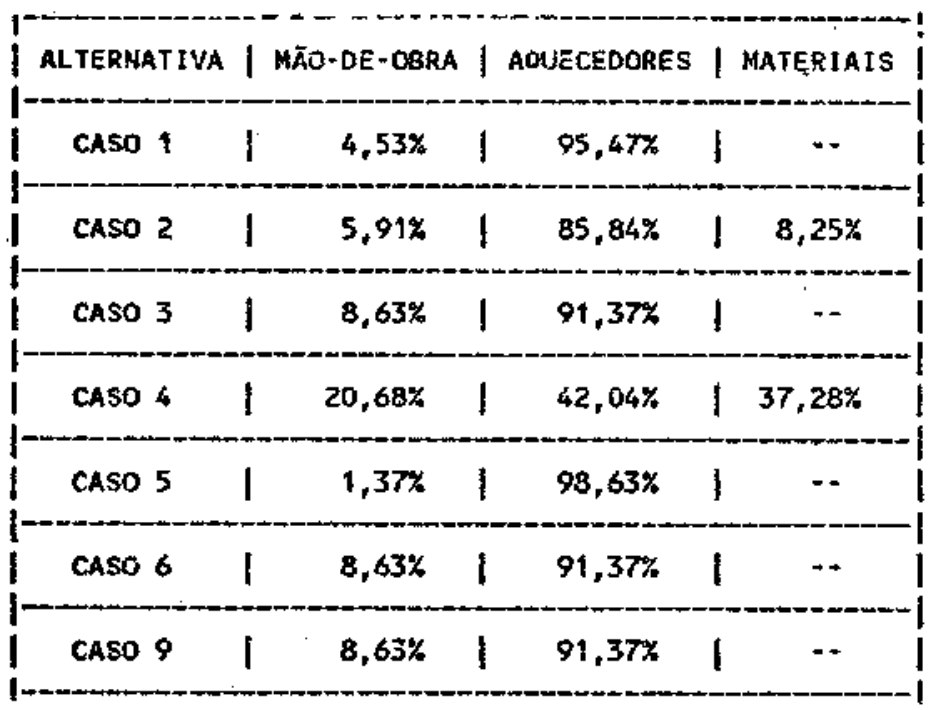

Semina, Ci. Exatas/Tecnol., v.12, n.4, p.230-235, dez. 1991 


\section{2 - Edificações Novas}

A partir do exame das Tabelas 3 a 6, apresentadas na seqüência, observa-se que:

- na instalação elétrica de uma edificação o custo do material apresenta nítida preponderância sobre o custo da mão-de-obra, exceto na Tipologia 3, onde, por razões inerentes, tais custos praticamente se eqüivalem;

- a economia que se faz na instalação elétrica por apartamento resulta tanto maior quanto mais alto for o padrão do apartamento, uma vez que se tem previsões excessivas de tomadas elétricas destinadas ao aquecimento de água; assim, quanto maior for o número de banheiros, mator será o número de previsões de tomadas de aquecimento de água e conseqüentemente maior a quantidade de material elétrico a ser utilizado; implantação de qualquer sistema hidráulico; novamente, a Tipologia 3 constitui exceção, especialmente em função do alto custo introduzido pelos equipamentos de aquecimento de água (no caso, aquecedores de passagem a gás), no lugar de chuveiros elétricos;

- a medição individualizada no sistema central coletivo (com uma coluna de distribuição de água quente por apartamento), tendo por base os casos examinados, introduz um aumento nos custos da ordem de $40 \%$ para a Tipologia 1 e de $16 \%$ para a Tipologia 4 , em relação ao mesmo sistema sem medição;

De sua vez, como o tempo necessário para se aquecer 1 litro de água com o equipamento a gás é, aproximadamente, 3 vezes menor que com o equipamento elétrico, foram obtidos os consumos de energético por litro, para

TABELA 3 - Tipologia 1: Orçamento geral da instalação elétrica (em US\$)

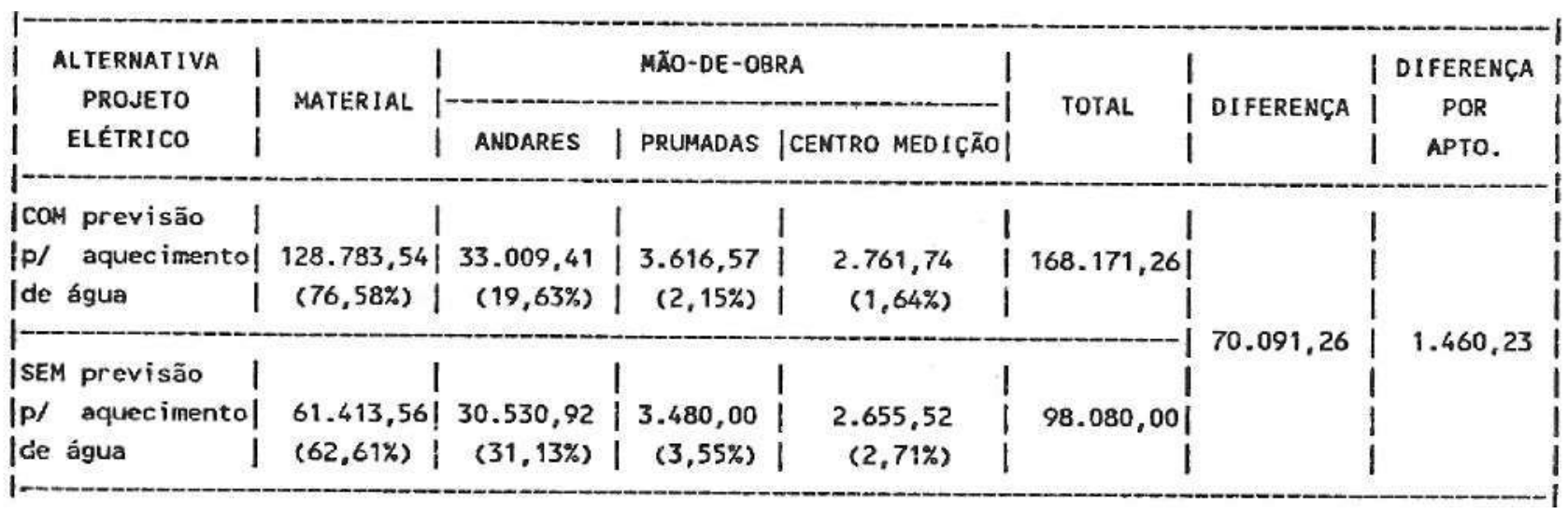

TABELA 4 - Tipologia 2: Orçamento geral da instalação elétrica (em US\$)

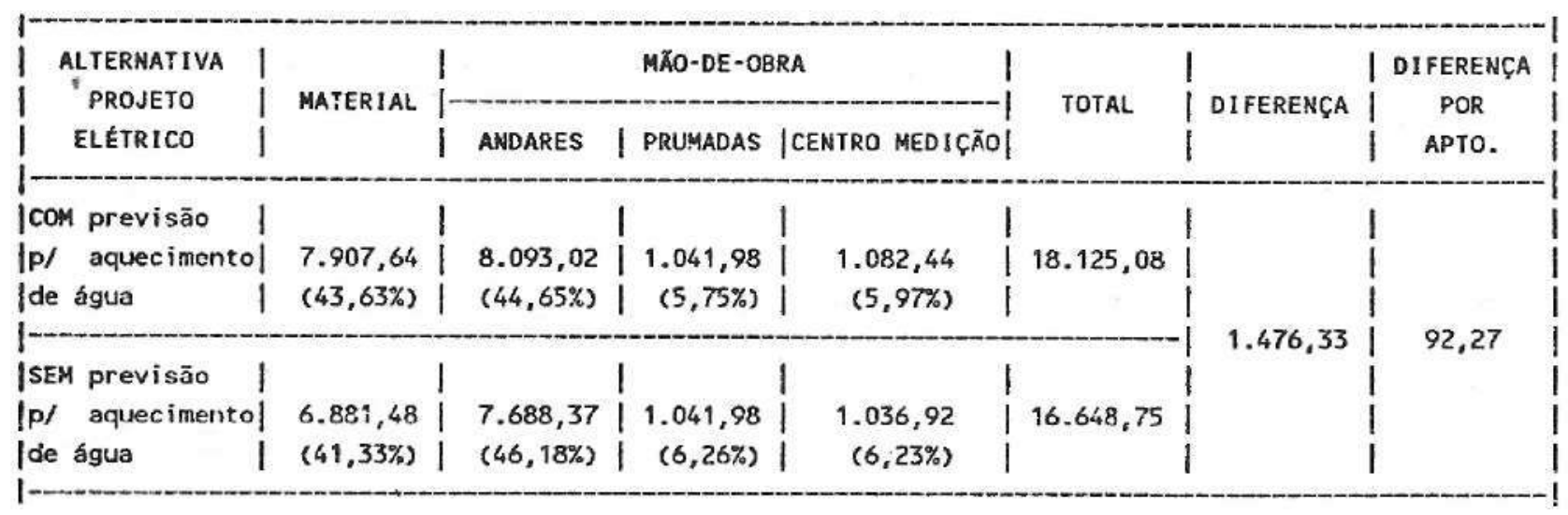

- tendo por base os casos analisados, pode-se chegar a uma economia de mais de $40 \%$ na instalação elétrica com a eliminação dos pontos (previsão de tomadas) destinados, única e exclusivamente, ao aquecimento de água; com a economia obtida na instalação elétrica, ao se eliminar tais pontos, verifica-se, adicionalmente, que podem ser cobertos, parcial ou totalmente, os custos relativos à uma diferença de temperatura (sobreaquecimento) de $50^{\circ} \mathrm{C}: 0,070 \mathrm{kWh}$ para os aquecedores elétricos e $0,0171 \mathrm{~m}^{3}$ para os aquecedores que utilizam gás de rua.

Uma vez que o gás de rua (natural) e a eletricidade apresentam a seguinte estrutura tarifária (maio de 1992):

- tarifa residencial de eletricidade (Eletropauio-SP):

- até $30 \mathrm{kWh}$.

Semina, Ci. Exatas/Tecnol.., v.12, n.4,p.230-235, dez. 1991 
TABELA 5 -Tipologia 3: Orçamento geral da instalação elétrica (em US\$)

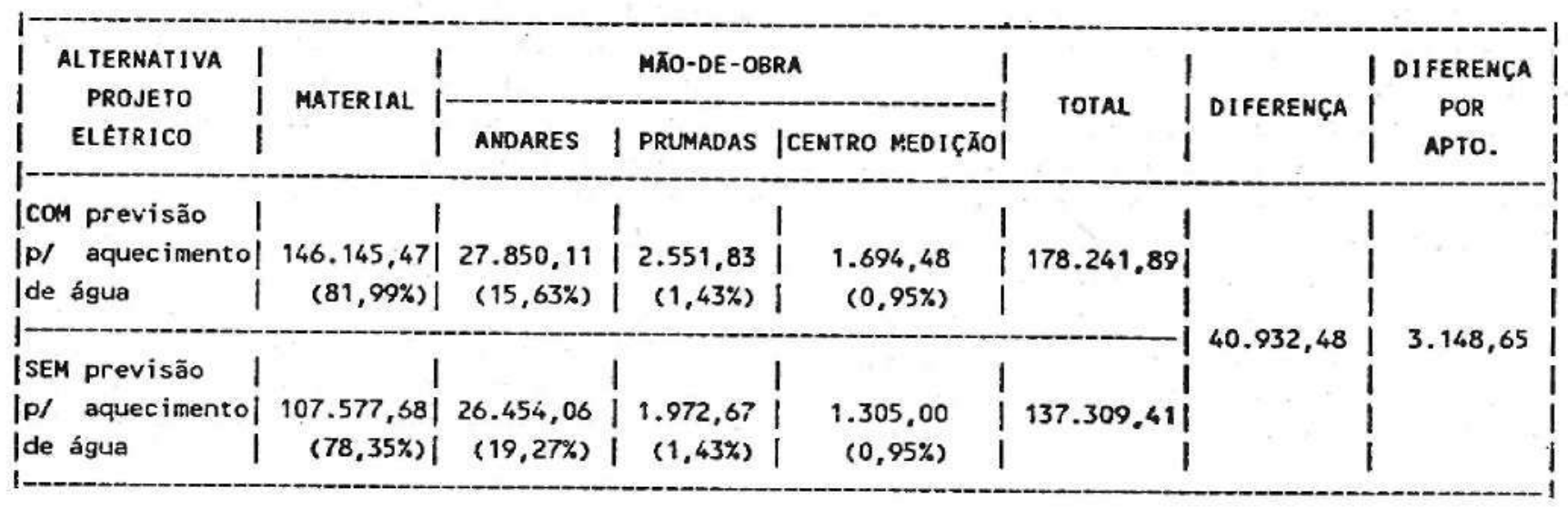

TABELA 6 - Comparação de custos das instalações hidráulicas (em US\$)

\begin{tabular}{|c|c|c|c|c|c|c|}
\hline & 1 & TIPOLOGSA 1 & 1 & TIPOLOGIA 4 & I & IIPOLOGIA 3 \\
\hline (PROS_HIDRÁULICO) & 1 & $\begin{array}{c}\text { (20/1B - } 12 \text { ANDARES } \\
4 \text { APYO/ANDAR })\end{array}$ & 1 & $\begin{array}{c}\text { (4D/3B - 13 AMDARES } \\
1 \text { APTO/ANDAR })\end{array}$ & 1 & $\begin{array}{c}\text { (2D/1B }-4 \text { ANDARES } \\
4 \text { APTO/AMDAR })\end{array}$ \\
\hline $\begin{array}{l}\text { Sistema Central Coletivo } \\
\text { SEN MEDIÇĀo }\end{array}$ & 1 & $44.052,12$ & 1 & $38.389,97$ & I & $\because$ \\
\hline $\begin{array}{l}\text { sistena Central Cotetivo } \\
\text { con MEDICĀo }\end{array}$ & I & $62.814,88$ & 1 & $45.954,57$ & i & $\cdots$ \\
\hline Sisterna Central Privado & 1 & $35.403,53$ & 1 & $43.890,31$ & 1 & $7.510,49$ \\
\hline
\end{tabular}

- de 31 a 100KWh ........US\$ 0,06976/kWh;

- de 101 a $200 \mathrm{kWh} \ldots . .$. US $\$ 0,07558 / \mathrm{kWh}$

. acima de 200kWh ...... US $\$ 0,11627 / \mathrm{kWh}$.

- tarifa (básica) residencial de gás de rua \{Comgás$\mathrm{SP})$.

- US\$ $0,13840 / \mathrm{m}^{3}$.

pode-se dizer que, se o uso de energia elétrica fosse exclusivamente para o aquecimento de água, e este fosse substituído pelo aquecimento a gás, ter-se-iam as faixas de consumo de gás e respectivos custos apresentados na Tabela 7 .

A nível governamental, tem sido adotada uma política tarifária de incentivo à conservação de energia, ao lado do aspecto social, estipulando-se tarifas mais baixas proporcionalmente ao consumo de energia elétrica. A partir disso, constata-se que, mesmo para a faixa de menor consumo (até $30 \mathrm{kWh}$ ), ou seja, aquela cujo o custo do $\mathrm{kWh}$ é mais baixo, o resultado chega a ser quase $38 \%$ maior que no caso da utilização do gás de rua. Por outro lado, para a faixa acima de $200 \mathrm{kWh}$ (sem subsídio), tal percentual é superior a $240 \%$.

Além disso, em muitos casos, a economia obtida na
TABELA 7 - Faixas de consumo e taxas correspondentes (Base: maio de 1992)

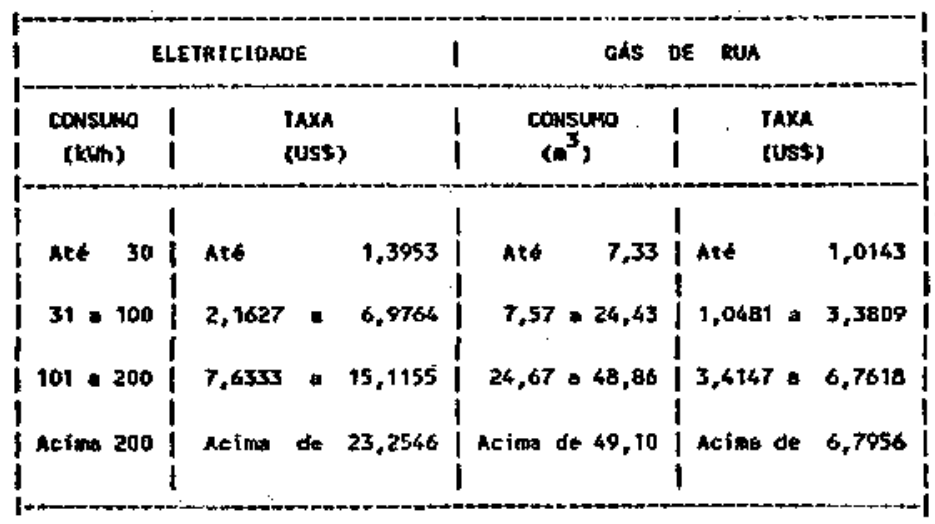

instalação elétrica resulta suficiente para pagar a instalação de água quente a gás combustível; naqueles casos em que isto não ocorre, a diferença pode se amortizar rapidamente em função da redução do custo operacional determinada pelo energético. 


\section{4 - CONCLUSÃO}

A partir da seleção prévia de quatro tipologias de edificações residenciais, segundo avaliação de um universo de ocorrências, tendo por base a escala final de aplicação, foram definidos Projetos Executivos que possibilitaram a análise técnico-econômica de cada caso de substituição de eletricidade por gás combustível no aquecimento de água, em edificações habitadas.

Os custos apresentados, evidentemente, devem-se somar àqueles decorrentes da implantação da rede de gás necessária ao aquecimento da água.

Como se referiu no item anterior, os custos totais se acham fortemente vinculados ao preço do equipamento, qualquer que seja o caso de substituição. A tendência à diminuição da influência deste fator ocorre nos casos em que há necessidade de execução de rede de água quente. Deve-se ressaltar, ainda, que nos casos de implantação de caldeiras a gás. os custos também tendem a ser tanto menores quanto maior for o número de unidades residenciais do edifício. Contudo, deve-se levar em consideração o estado de conservação do equipamento a ser substituída, face ao seu tempo de uso.

No caso das edificações novas, também a partir da elaboração dos Projetos Executivos de instalações de água quente nos edifícios selecionados, procedeu-se ao orçamento e à análise econômica, sendo possível alinhavar as seguintes conclusões gerais, para as diversas situações examinadas:

- a economia que se obtém com a eliminação dos pontos destinados ao aquecimento de água na instalação elétrica amortiza, parcial ou, como na maioria dos casos, totalmente, os custos da instalação hidráulica de água quente com aquecedor a gás;

- a economia acima referida, por apartamento, aumenta à medida que se eleva o padrão da unidade residencial; •
— a introdução da medição individualizada no sistema central coletivo, admitindo-se uma coluna de distribuição de água quente por apartamento, eleva em certa extensão os custos em relação ao mesmo sistema sem medição (em torno de $40 \%$ para a Tipologia 1 e cerca de $16 \%$ para a Tipologia 2);

- o custo operacional no aquecimento de água, em termos do consumo de energético, apresenta-se bem menor para o gás de rua, comparativamente à eletricidade, indicando uma rápida amortização dos custos com a instalação de água quente a gás, inclusive naqueles casos em que a aludida economia, com a eliminação dos pontos previstos na instalação elétrica, não foi suficiente.

Finalmente, deve-se salientar alguns tópicos relevantes, mesmo que não tenham sido mencionados de maneira explícita ao longo do presente trabalho:

— instalação do equipamento gerador de água quente e adequação do ambiente (distâncias, chaminé, ventilação, etc);

- aperfeiçoamento dos equipamentos atualmente existentes (aquecedores de acumulação com menores capacidades, queimador piloto com menor consumo, adequação das características de capacidade de recuperação e volume de armazenamento, aquecedores com chama modulável, etc);

- diminuição dos custos de implantação (aplicação de materiais alternativos, etc);

- desenvolvimento de novos componentes (aquecedores de fluxo balanceado, misturadores e válvulas termostáticos, cabos automáticos de aquecimento, etc);

- utilização de técnicas e critérios mais avançados de dimensíonamento (como a modelagem probabilfstica utilizada no presente trabalho); de campo;

- programa de levantamento sistemático de dados

- modernização da Normalização Brasileira (normas de procedimento de projeto, normas de componentes, etc).

KAVASSAKI, V.; ILHA, M.S. de; GONÇALVES, O.M. The replacement of electricity by combustible gas in the domestíc water heatíng. Semina, v. 12, n.4, p.230-235, Dec. 1991.

\section{ABSTRACT}

The context of energy crisis hints conserving measures and effective use of primary forms of energy, in order to balance their availability and the ever-growing demand for them. In the domestic sector, the curve of electricity demand reveals the peaks caused by the hot water production. Thus, both technical and economical evaluation are carried out for many cases replacing eletricity by combustible gas in the domestic water heating; both new and occupied residential buildings are taken into account in the present survey.

KEY WORDS: Hot water, Building hot water systems, Water heating, Energy conservation.

\section{REFERÊNCIAS BIBLIOGRÁFICAS}

1 - GONÇALVES, O.M. Formulação de Modelo para o Estabelecimento de Vazōes de Projeto em Sistemas Prediais de Agua Fria. Tese de Doutorado, EPUSP, 1986, 369p.

Recebido para publicação em 1/6/1992 